http://jmscr.igmpublication.org/home/

ISSN (e)-2347-176x ISSN (p) 2455-0450

crossref DOI: https://dx.doi.org/10.18535/jmscr/v9i11.17

Journal Of Medical Science And Clinical Research

\title{
Guillian-barre Syndrome as one of the Rare Manifestation of Systemic lupus Erythematosus- A Rare Case Report
}

\author{
Authors \\ Saumya Ranjan Sahoo ${ }^{1}$, Taranisen Sethi ${ }^{2}$ \\ ${ }^{1}$ Junior Resident, Department of General Merdicine, VIMSAR, Burla \\ ${ }^{2}$ Junior Resident, Department of General Medicine, VIMSAR, Burla
}

\begin{abstract}
Systemic lupus erythematosus (SLE) is an autoimmune disorder being mediated by immunocomplexs and autoantibodies and INF-Alpha is the key mediator. Among neurological manifestations Guillian barre syndrome $(G B S)$ is one of the rare presentation. We described a 35 year female who developed acute onset progressive ascending quadriparesis with tingling and numbness of bilateral lower limb. NCS showed acute motor sensory axonal polyneuropthy. The patient had diffuse non scarring alopecia with anaemia with proteinuria and both ANA and anti-dsDNA were reactive. The patient improved with pulse dose of methylprednisolone and i.v immunoglobin $(2 \mathrm{gm} / \mathrm{kg}$ body weight $)$ and discharged with hydroxychloroquinie and low dose of prednisolone.
\end{abstract}

\section{Introduction}

Systemic lupus erythematosus (SLE) is characterized by heterogeneous, multisystem involvement and the production of an array of autoantibodies, immune complex mediated disease. The complex process is triggered by genes, female hormones, environmental factors like UV light, smoking and infections like EBV. Neuropsychiatric systemic lupus erythematosus (NPSLE) as described by the American College of Rheumatology (ACR) research committee includes 19 neuropsychiatric syndromes divided into neurologic syndromes of the central, peripheral, and autonomic nervous system and the psychiatric syndromes observed in patients with SLE in which other causes have been excluded. These symptoms may precede the onset of SLE or can occur at any time during the course of SLE ${ }^{[1]}$. However, to the best of our knowledge, few cases have been reported in the last 50 years in which the initial manifestation of SLE was GullianBarre syndrome $(\mathrm{GBS})^{[2]}$

\section{Case Report}

A 35-year-old female presented with tingling and numbness of both the lower limbs with weakness of both the limbs which was sudden onset progressive ascending type and gradually involved both the upper limbs in span of 2 days. She got bed ridden and came under Hugh score 3.There was no bladder and bowel involvement. There was no muscle fasciculation, no headache, nausea, vomiting, no blurred vision, no difficulty in swallowing and drinking. There was no history of vaccination. There was no antecedent fever, loose stool episodes in past 1 month. The patient is not a known case of diabetes mellitus, chronic kidney disease, any thyroid disorder. 
On examination patient was afebrile, respiratory rate $18 / \mathrm{min}$, blood pressure of $126 / 70 \mathrm{~mm}$ of $\mathrm{Hg}$. The patient had diffuse non scrarring alopecia. On neurological examination tone was diminished in both upper and lower limb with no atrophy. Power was $3 / 5$ proximally and 4/5 distally in both upper and lower limbs. All the DTRs are diminished. Paresthesia was there in distal limbs in gloves and stoking patterns. There was also fine touch and vibration lost up to mid of $b / 1$ legs and hands.

Lab data showed anemia was there with $\mathrm{Hb} 10.2$ $\mathrm{gm} / \mathrm{dl}$. TLC and TPC were in normal limits. Serum urea and creatinine were normal. LFT was normal. There was hypoalbuminemia (albumin was $2.4 \mathrm{gm} / \mathrm{dl}$ ). Urinalysis revealed protein was $3+.24 \mathrm{hr}$ urine protein came out to be $12.4 \mathrm{gm}$. The ESR was 45. Serological tests for HIV, hepatitis $\mathrm{B} / \mathrm{C}$ were negative. The ANA was 8.7 units (>1.2 -Positive), anti-dsDNA was $>150 \mathrm{IU} / \mathrm{ml}$ (30 IU/ml-positive). Antiphospholipid antibodies were negative. CSF study revealed albumin-cytological dissociation (total protein: $153 \mathrm{gm} / \mathrm{dl}$, total cell count: $3 / \mathrm{microlit}$ ). Contrast MRI was normal. Nerve conduction study revealed non of the Motor Nerve Conduction Velocity (MNCV) and Sensory Nerve Conduction Velocity(SNCV) was generated in any of the four limbs and also F-wave was not generated which was in more favour of motor sensory axonal polyneuroradiculopathy. The patient was improved with pulse dose of methylprednisolone $1 \mathrm{gm}$ daily for 5 days with IVIG $2 \mathrm{gm} / \mathrm{kg}$ over 5 days. Then the patient was discharged with Hydroxychloroquine, and low dose prednisolone.

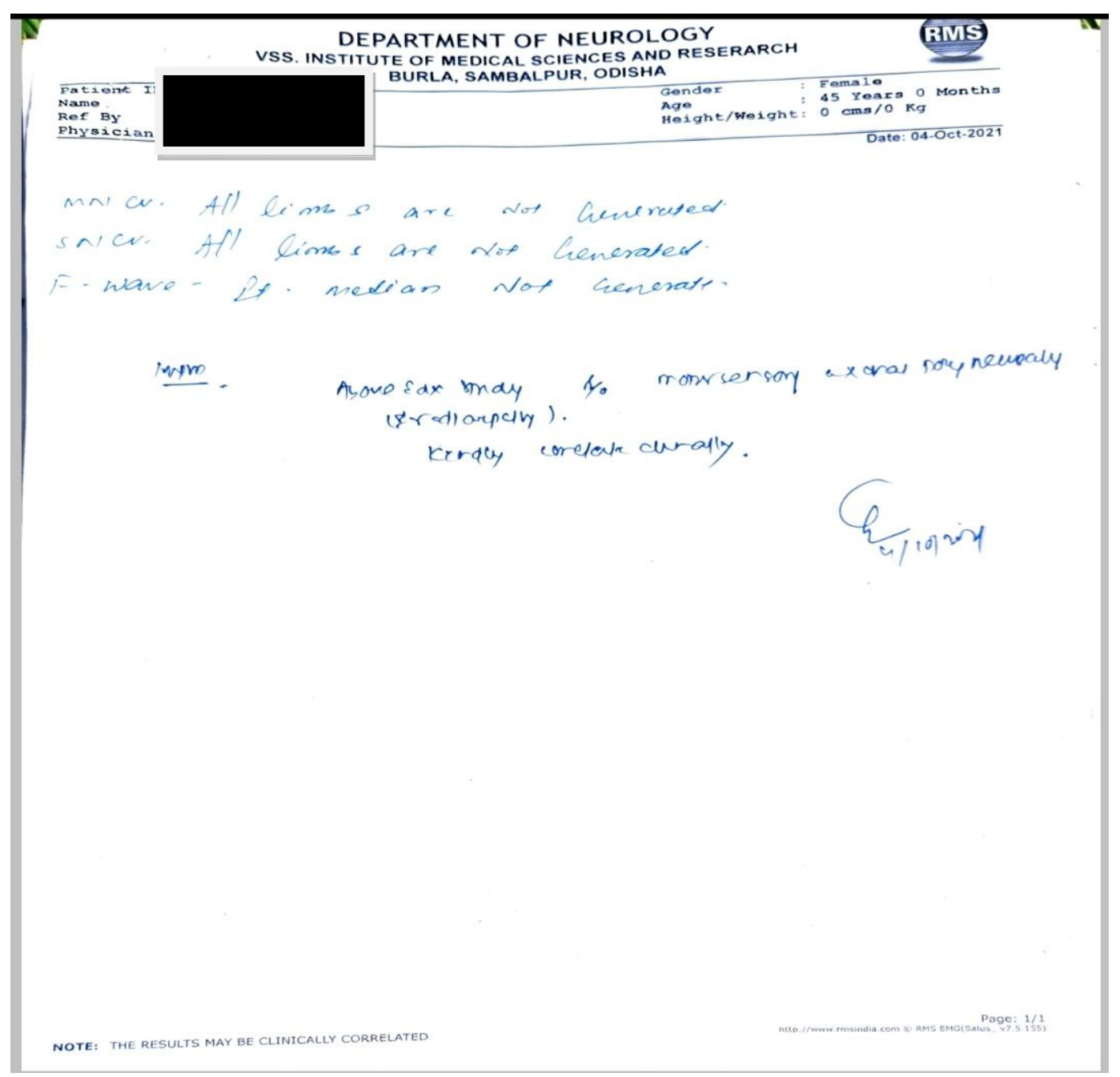




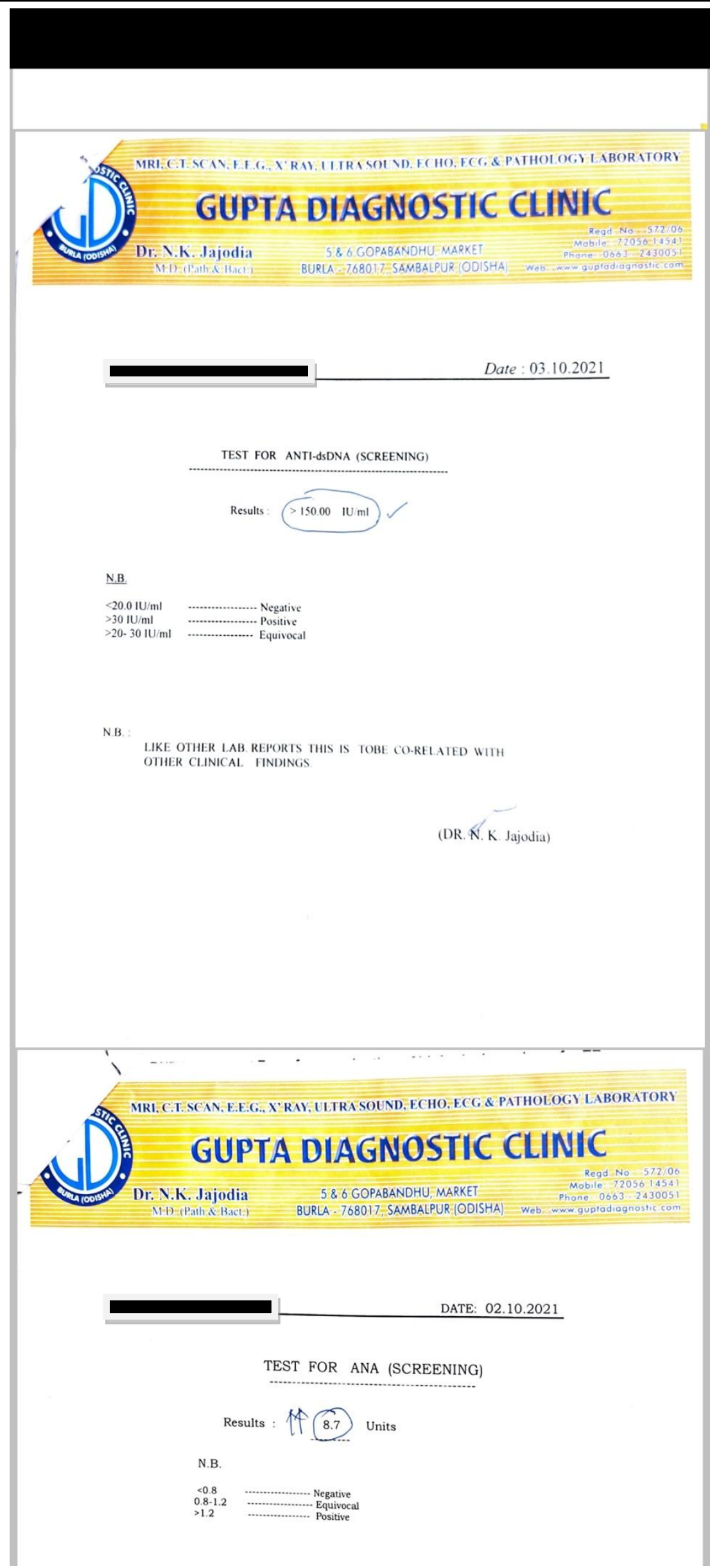






\section{V.S.S.INSTITUTE OF MEDICAL SCIENCES \& RESEARCH,
BURLA. SAMBALPUR (ODISHA)CENTRAL LABORATORY(RDC)}

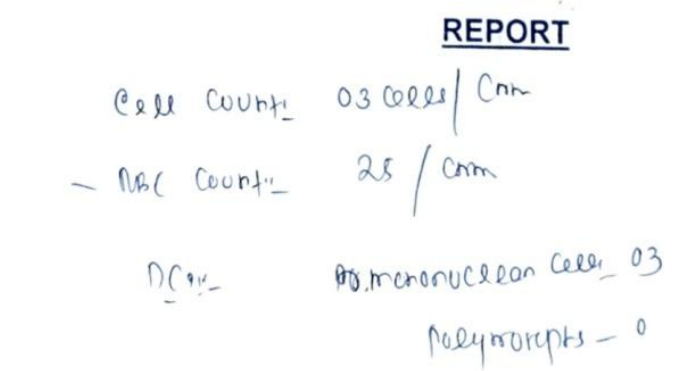

mpression:-

\section{Discussion}

The signs and symptoms in the presented patient, fulfilled the Asbury criteria ${ }^{[3]}$ and $\mathrm{ACR}^{[1]}$ case definitions for the diagnosis of GBS. Various forms of lupus related polyneuropathy have been reported in $10-20 \%$ of patients with SLE $^{[4]}$. However, GBS which is a demyelinating polyneuropathy, is a rare complication in lupus ${ }^{[5,6]}$. The prevalence of SLE with GBS has been reported to be between $0.6 \%$ and $1.7 \%^{[7,8]}$. The pathogenesis of GBS as a manifestation of active SLE is not clear, but both cell-mediated and humoral processes may play a significant role ${ }^{[6] \text {. }}$ There are currently four kinds of anti-neuronal antibodies: antilymphocytic antibodies, antiphospholipid antibodies (including cardiolipin antibodies and lupus anticoagulants), and antiribosomal $\mathrm{P}$ protein antibodies. These antibodies are often present in the plasma and cerebrospinal fluid, and they cause more extensive neurological damage. Corticosteroids, cyclophosphamide, plasmapheresis, and immunoglobulin have been used in AIDP or GBS with SLE according to the previous literature. The combination of corticosteroids and cyclophosphamide is considered the first-line treatment option in a review of the literature ${ }^{[9] .}$

\section{Conclusion}

Our case shows GBS can be one of the initial presentations of SLE which was successfully treated by IVIG and pulse dose of 
methylprednisolone. Still more researches are required to find the pathogenesis and treatment options of both the disease.

\section{Conflict of Interests: No}

\section{References}

1. "The American College of Rheumatology nomenclature and case definitions for neuropsychiatric lupus syndromes," Arthritis \& Rheumatism, vol. 42, no. 4, pp. 599-608, 1999. View at: Publisher Site | Google Scholar

2. Millette TJ, Subramony SH, Wee AS, et al. Systemic lupus erythematosus presenting with recurrent acute demyelinating polyneuropathy. Europ Neurol 1986;25:397-402. [PubMed] [Google Scholar]

3. Asbury AK, Cornblath DR. Assessment of current diagnostic criteria for GuillainBarré syndrome.Ann Neuro/1990;27:2124.

4. Levin KH. Variants and mimics of Guillain-Barre syndrome. Neurologist 2004;10:61-74. [PubMed] [Google Scholar].

5. Chaudhuri KR, Taylor IK, Niven RM, et al. A case of systemic lupus erythematosus presenting as Guillain-Barre syndrome. $\mathrm{Br}$ J Rheumatol 1989;28:440-2. [PubMed] [Google Scholar].

6. Robson MG, Walport MJ, Davies KA. Systemic lupus erythema-tosus and acute demyelinating polyneuropathy. $\mathrm{Br} \mathrm{J}$ Rheumatol 1994;30:314-6. [Google Scholar]

7. Korn-Lubetzki I, Abramsky O. Acute and chronic demyelinating inflammatory polyra-diculoneuropathy. Association with autoimmune diseases and lymphocyte response to human neuritogenic protein.
Arch Neurol 1986;43:604-8. [PubMed] [Google Scholar].

8. Nadri Q, Althaf MM. Guillian-Barre syndrome as the initial presentation of systemic lupus erythematosus - case report and review of literature. Ann Saudi Med 2015;35:263-5. [PMC free article] [PubMed] [Google Scholar]

9. van Laarhoven HW, Rooyer FA, van Engelen BG, et al. Guillain-Barre syndrome as presenting feature in a patient with lupus nephritis, with complete resolution after cyclophosphamide treatment. Nephrol Dial Transplant 2001; 16:840-2. [PubMed] [Google Scholar] 